\title{
Iron Stress in Citrus
}

\author{
Maria Angeles Forner-Giner and Gema Ancillo \\ Instituto Valenciano de Investigaciones Agrarias (IVIA) \\ Spain
}

\section{Introduction}

Iron is an essential element for plant growth and development, since it is fundamental for the proper functioning of numerous metabolic and enzymatic processes. Calcareous soils with restricted iron availability for plants are commonly found in the Mediterranean basin where citrus are the major fruit crop. The genus Citrus and related rootstocks species are considered to be susceptible to iron chlorosis. Iron deficiency tolerance is determined by the rootstock so citrus trees display differences in susceptibility according to the rootstock they have been grafted on.

Field trials have been carried out to select chlorosis-tolerant genotypes. Evaluation of growth and yield parameters may not be sufficient to rank citrus rootstocks according to their tolerance to iron chlorosis, and in addition, field trials take a long time to obtain results. Greenhouse screening tests are easier to implement than field trials in order to evaluate the tolerance. Several physiological parameters are measured in order to test the tolerance to iron deficiency. Nevertheless new screening techniques are needed to identify chlorosis-tolerant genotypes which can be used in breeding programs.

\section{Iron chlorosis in plants}

The term "essential mineral nutrient" was initially proposed by Arnon \& Stout (1939) and applies to all elements necessary for to develop life and reproduction of plants. A plant can complete its life cycle if it is supplied in sufficient quantity and every one of the minerals that are essential. There are two aspects to consider a nutrient as essential. The first one is that the requirement on the element must be specified and can not be replaced by another, and the second one is that the elements must have a direct influence on the metabolism of plants.

The Fe is involved in important processes as photosynthesis, respiration, metabolism of proteins, fixation and nitrogen assimilation and nitrate reduction (Romera \& Guardia, 1991). It is also a cofactor for enzymes (such as cytochrome oxidase, catalase (EC 1.11.1.6) and peroxidase (EC 1.11.1.7) that catalyze biochemical reactions only, making it essential role in the growth and development of plants (Abbey, 1992; Larbi et al. 2006; Molassiotis et al. 2006; Agustí, 2003).

Of the two oxidation states that iron may occur in the soil: ferric $(\mathrm{Fe} 3+)$ and ferrous $(\mathrm{Fe} 2+)$, it is accepted that the plant takes preferably the latter, for this plant is forced to reduce the predominant form of iron in aerobic soils $(\mathrm{Fe} 3+)$. This process is performed by a reductase enzyme located in the plasma membrane of the root (Bienfait 1985; Römheld 1987). This enzyme reaches its maximum activity at pH between 4 and 5 (Schmidt \& Bartels 1997). On 
the other hand, extreme temperatures (significantly above or below $25^{\circ} \mathrm{C}$ ), $\mathrm{pH}$ values greater than 7.5 and the presence of heavy metals affects their activity (Lucena 2000).

$\mathrm{Fe}$ is involved in such important processes as photosynthesis, respiration, metabolism of proteins, fixation and nitrogen assimilation and nitrate reduction (Romera \& Guard 1991). It is also a cofactor for enzymes (such as cytochrome oxidase, catalase (EC 1.11.1.6) and peroxidase (EC 1.11.1.7) that catalyze biochemical reactions only, making it essential role in the growth and development of plants (Abbey 1992; Larbi et al. 2006; Molassiotis et al. 2006; Agustí 2003).

Chlorosis means lack of chlorophyll in a plant organ, resulting in a loss of green color. Chlorosis can be caused by both the supply deficit of essential elements for plant growth (Fe, manganese $(\mathrm{Mn})$, magnesium $(\mathrm{Mg})$, zinc $(\mathrm{Zn})$, nitrogen $(\mathrm{N})$, etc), water stress or pests, fungi, bacteria or viruses. Iron deficiency, also called iron chlorosis, is one of the most important abiotic stresses. The causes of iron deficiency are numerous and vary, highlighting the availability of iron and bicarbonate ion concentration in the middle of development and other factors. Iron deficiency is usually caused by an insufficient concentration of it in the soil, but the existence of several factors makes affect the solubility and mobility of the Fe. These factors may be a high $\mathrm{pH}$ insolubilice some compounds, there limestone and other components, redox potential, interaction between $\mathrm{Fe}$ and other nutrients, moisture, organic amendment, salinity, extreme temperatures, etc. (Tagliavini \& Rombola 2001). The low availability of iron is increased in soils with the presence of high bicarbonate levels that make the $\mathrm{pH}$ is around 8 (Marchner \& Römheld 1995), this $\mathrm{pH}$ the concentration of Fe quite low and therefore difficult to iron nutrition of the plant (Lucena et al. 2006a). The problem of iron chlorosis is widespread because the limestone soils occupy approximately $30 \%$ of the land surface (Chen et al. 1982). It is estimated that between 20 and $50 \%$ of fruit growing in Mediterranean areas deficient in iron (Jaeger et al. 2000).

Some higher plants, in the absence of Fe have developed a number of mechanisms to increase the availability of Fe in the soil solution. Strategy I plants increase the Fe-making by the excretion of reducing substances of low molecular weight, through the extrusion of protons by roots acidifying the rhizosphere, solubilizing nutrients not available in an alkaline medium (Jones 2000) and increasing the activity of a reductase associated with the plasma membrane of the root responsible for the reduction of Fe $3+$. Other, as the formation of root hairs and transfer cells in the root occur before or simultaneously with the physiological responses, which suggests that structural alterations may be a prerequisite for the functioning of mechanisms for efficient Fe (Landsberg 1986).

In higher plants $\mathrm{Fe}$ is predominantly found in chloroplasts, thus iron deficiency affects almost exclusively to the chloroplast, while the other cellular organelles that contain iron, such as peroxisomes, endoplasmic reticulum, mitochondria, etc.. seems to remain unchanged (Platt-Aloia et al., 1983).

Most of the mobilized Fe in plants is a phosphoprotein in the form of iron, the fitoferritina. The chloroplasts can contain up to $80 \%$ iron plant as fitoferritina (Tiffin, 1972).

The effect of Fe deficiency results in decreased concentrations of photosynthetic pigments and other components of the thylakoid membrane (Morales et al., 1991, 1994). Iron-deficient plants have less chlorophyll per unit chloroplast, but the number of these does not decrease per unit leaf. However, reducing the amount of chlorophyll is accompanied by alteration of the structure and functions of the chloroplast, reducing both the number and degree of stacking of the thylakoid membranes (Spiller \& Terry, 1980, Terry \& Abadía, 1986; Terry \& Zayed, 1995; Soldatini et al., 2000). 
The reduction of the thylakoid membrane is accompanied by decreased concentrations of photosynthetic pigments (chlorophylls $\mathrm{a}$ and $\mathrm{b}$ and carotenoids) in the leaves of affected plants (Morales et al., 1990, 1994). The loss of leaf pigments sheet does not imply that diminish their ability to capture light energy (Terry \& Zayed, 1995) due in part to the increase in the relationship leaf carotene / chlorophyll concentrations decline with leaf carotene deficiency Fe to a lesser degree than the chlorophylls (Terry, 1980, Morales et al., 1990, 1994, 2000). The characteristic yellow chlorotic leaves is a consequence of the imbalance between the contents of chlorophyll and carotenoids (Abbey, 1992, Terry \& Zayed, 1995).

Iron is also involved in chlorophyll synthesis (Miller et al., 1984) in different crops subject to conditions of deficiency, has shown an increase in the ratio of chlorophyll a: chlorophyll b (Abbey et al. 1989; Monge et al., 1987, Nishio et al., 1985). One explanation for this increase is that under conditions of iron deficiency in the field and there is full sunlight preferential photodestruction of chlorophyll b (Díez-Altar, 1959). Fe deficiency also increases the activity of chlorophyllase, which is involved in the degradation of chlorophyll in citrus fruits (Fernandez-Lopez et al., 1991).

Finally, iron is a constituent of many electron transporters (Terry \& Abadía, 1986; Abbey, 1992, Terry \& Zayed, 1995; Soldatini et al. 2000), so that iron deficiency is also reduced photosynthetic electron transport. These facts lead to a reduction in photosynthetic capacity of the plant that results in decreased levels of sugars, starch, certain amino acids and accumulation of others, thus altering the spectrum of proteins (Terry \& Abadía, 1986; Abbey, 1992, Terry \& Zayed, 1995) and enrichment in unsaturated lipids (Terry \& Abadía, 1986; Abbey, 1992, Terry \& Zayed, 1995), which alters the physiological functioning of the plant. The reduction in plant growth may be related to decreased photosynthetic capacity of chlorotic leaves. Both vegetative growth and production decrease with iron chlorosis (Hurley et al., 1986). The low capacity of the plant to translocate iron from old leaves, is manifested by the yellowing of young leaves, except their nerves remain green. These outbreaks are becoming less vigorous and its leaves, small, can fall prematurely, starting with the most apical (Agustí, 2003). One can also induce severe chlorosis reduced stem growth by inhibiting the formation of new leaves (Loue, 1993). Reducing the number and final size of the fruit, as well as total soluble solids content of the juice are also consequences that result from a deficiency of Fe (Agustí, 2003).

\section{Effects of iron chlorosis in citrus}

Many agricultural crops in arid and semiarid regions suffer chlorosis. Among the plants most affected are the citrus, planted in chalky soils often show signs of severe iron deficiency (Wallace, 1986). Iron chlorosis affects many biochemical, morphological and physiological parameters, and therefore their growth and development of plants (Larbi et al., 2006, Molassiotis et al., 2006, Agustí, 2003).

Iron deficiency in citrus tends to be observed during the months of winter and spring. And internervial yellowing of the leaves of young shoots are manifested, due to the inability of the plant to translocate iron from old leaves. The loss of pigmentation is caused by decreased chlorophyll content in chloroplasts (Marschner, 1995). This negatively affects the rate of photosynthesis and, therefore, the development of biomass (Abbey et al., 2004). The young shoots are becoming less vigorous and its leaves, small, can fall prematurely, starting with the most apical (Agustí, 2003). 


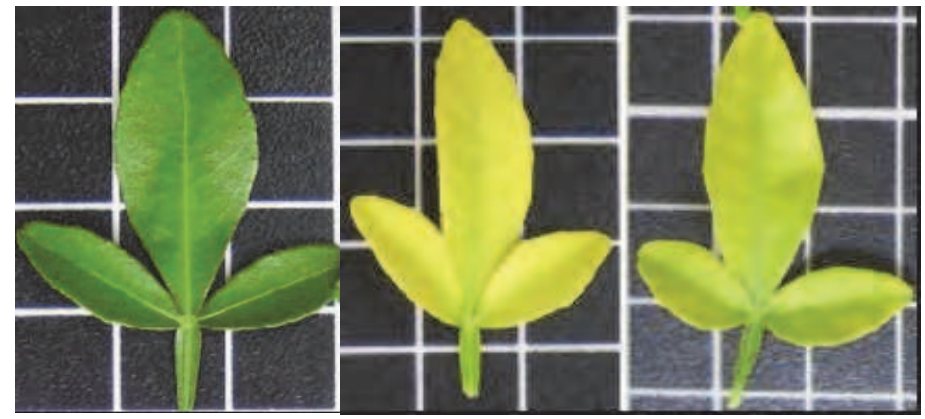

Fig. 1. Control and chlorotic leaves of citrange Carrizo.

In the case of a more serious deficiency, loss of pigmentation may also affect adult leaves, and the younger end completely yellow and devoid of chlorophyll. The fruits are also affected by severe iron deficiency. It reduces the number of fruits and their growth shortly after the set and these become yellow unexpected; Also decreases the concentration of juice soluble solids (Amorós, 1995; Agustí, 2003).

The treatment for iron chlorosis can be started before it appears, preventing the causes that lead. The best preventive practices include avoiding certain combinations plantations growing on soils unsuitable or use of tolerant cultivars. Once detected the symptoms of iron chlorosis trees can be treated with corrective methods to increase the availability of iron (Wallace, 1991), avoiding a loss of production (Pestana et al., 2001b). In cases of late diagnosis, will not be able to avoid the loss of annual production, but could be enhanced vegetative growth for the next harvest (Abbey et al., 2004). It has been described different types of treatments to correct iron chlorosis. Most important are foliar application, soil application and trunk injections. Foliar applications are very fast acting and can be less expensive than soil-applied treatments (Pestana et al., 2003), but have disadvantages of short-lived effects and cause phytotoxicity in certain cases (Wallace et al. 1984; Mortvedt, 1986), as well as cause the appearance of burns, defoliation, the greening in spots and no effect on the leaves that develop after treatment (Legaz et al., 1992, García et al., 1998; Fernández \& Ebert, 2005). Thus foliar treatments are effective only in situations of symptoms of mild to moderate chlorosis (Rombolá et al., 2000). Moreover, Pestana et al. (2001a) indicated that foliar application of FeSO4 in citrus avoid losses in production and quality of fruits caused by it. The same authors found that several foliar applications are able to relieve iron chlorosis in field trials. The application of ferrous sulfate was more effective in increasing the size and quality of the fruits that the Fe (III)-chelate. Pestana et al. (2001b) also indicated that the addition of sulphuric acid produced a small increase in the concentration of chlorophyll and Fe in the leaves, without causing any effect on the size and quality of fruit. The same authors concluded that foliar application can reduce production losses and quality of fruits caused by iron deficiency.

Injections into the trunk and branches consist of introducing iron compounds either in solid or in solution, by drilling into the wood. This type of treatment is recommended for mature trees in which has a big trunk diameter. Both the solid and the liquid injection under high pressure have the advantage of having a great effect and great persistence of treatment, usually two or more years (Hurley et al., 1986, Yoshikawa, 1988). The major drawback to injections of solid type is the need for a large number of holes around the trunk, which 
sometimes leads to problems of gumming (Heras et al., 1976). The main disadvantages of high pressure fluid injections are its high cost, because we have to move to field a pressure generating equipment with an injection machine (Yoshikawa, 1988).

Land application of iron fertilizer is the most widely used practice, and is done once the chlorosis appears in the crop (Pestana et al., 2003). The iron is supplied to the soil as chelates. Chelates are organic substances containing Fe in stable molecules. The iron remains assimilable by plants and doesn't suffer the insolubilization reactions of this type of soils. The most commonly used is chelated Fe (III)-EDDHA and is often added to irrigation water (Papastylianou et al., 1993). Zude et al. (1999) showed that application of chelated iron in the soil produces a greening of Fe-deficient leaves of citrus. The same authors also indicated that both the chlorophyll content and photosynthesis increase after the application of Fe chelates.

\section{Screening citrus rootstocks to iron chlorosis}

Citrus trees grown today are composed of two parts, the rootstock and the variety, the second grafted onto it first, so that together combine the best features possible. In the screening citrus for iron chlorosis, the selection of plant material has to be done primarily, being the rootstock the determinant of tolerance to chlorosis. The performance of citrus rootstocks with iron chlorosis is very variable. Thus, although development is not limited by low levels, elevated content in active lime limit their use. The sensitivity of a rootstocks to elevated levels of iron chlorosis has many symptoms, on which also affected by other factors such as soil rich in calcium carbonate, calcium, moisture, $\mathrm{pH}$ and the grafted variety (Agustí, 2003).

The Swingle citrumelo is very sensitive to iron chlorosis. The rootstocks P. trifoliata, Carrizo citrange and sweet orange are susceptible to lime-induced chlorosis, while the sour orange and Cleopatra mandarin are tolerant to this deficiency (Hamza et al., 1986, Castle, 1987; Treeby \& Uren, 1993; Pestana et al., 2005). Cleopatra mandarin are tolerant to iron chlorosis, but grows slowly in the field. Besides the production of fruit is not very high and although the fruit is of good quality, is smaller than that produced on other rootstocks.

There is a citrus rootstock breeding program taking place in the IVIA (Valencia, Spain) with the objective of the search for new citrus rootstocks well adapted to calcareous soils. In this regard, a new hybrid is now available in Spanish citrus nurseries: Forner-Alcaide 5 (FA 5) (Cleopatra mandarin $\times$ P. trifoliata). This rootstock has been evaluated from an agronomic point of view in calcareous soils (Gonzalez-Mas et al., 2009; Llosá et al., 2009) and it is more tolerant than Carrizo citrange, and trees 'Navelina' grafted in FA 5 produce $40 \%$ more than the trees grafted on Carrizo citrange, with the smaller fruit but equal quality to those of trees grafted on Carrizo (Forner et al., 2003, Forner-Giner et al., 2003).

There is no a perfect rootstock. All citrus rootstocks, that are currently used in the world, have some limitations. Over the years, every citrus producing area has been selected those rootstocks best suited to their conditions. However, there are still many areas for which there is no pattern can solve all their problems properly. Currently, there is large number of studies aimed at looking for a methodology for assessing the tolerance to iron chlorosis of citrus rootstocks (Castle, 2010; Gonzalez-Mas et al., 2009; Llosá et al., 2009). So far, that assessment could only be done reliably in field tests. The fruit breeding rootstocks represents the most cost-effective and sustainable solution to the problem of iron deficiency (Cianzio, 1995; Wirén, 2004). 


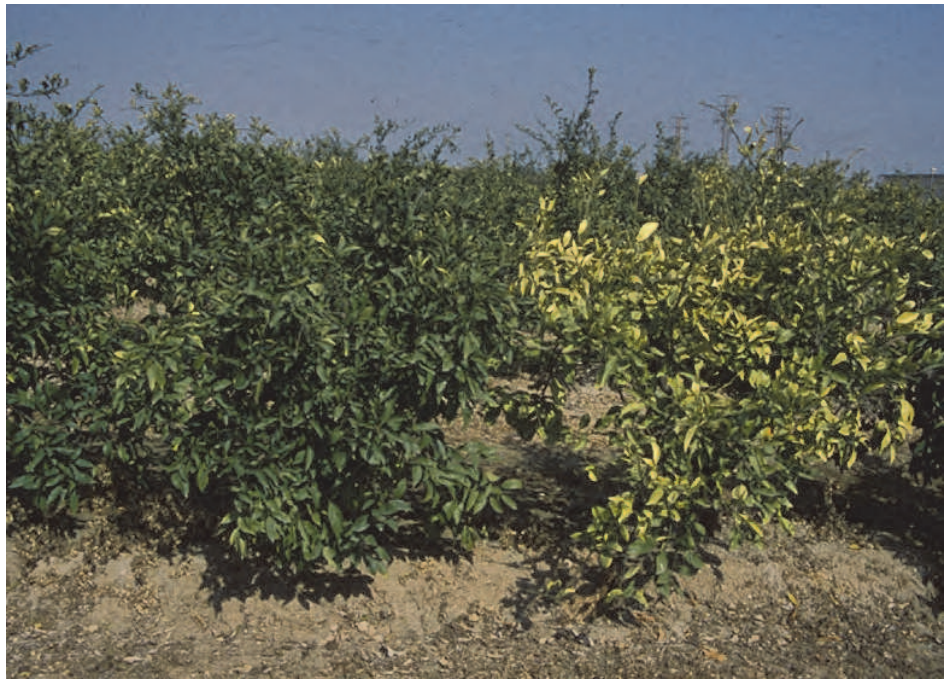

Fig. 2. Differences between a tolerant (left) and susceptible (right) citrus rootstock

\section{Molecular mechanisms underlying iron deficiency in citrus}

The molecular components that are involved in the Fe deficiency response have been poorly identified and only in isolated cases. Mechanisms by which plants adapt to Fe deficiency have been frequently described in grasses (Strategy II) and other plants (strategy I) (Moog \& Brueggemann, 1994). Strategy I (which is the one followed by Citrus) relies on increasing iron solubility by inducing membrane-bound Fe(III)-chelate reductases that reduce Fe(III) to $\mathrm{Fe}(\mathrm{II})$, which is more soluble and is subsequently taken up by specific transporters (Chaney et al. 1972).

In citrus, little is known about the behaviour at a molecular level of of the Fe(III)-chelate reductase in response to $\mathrm{Fe}$ starvation. Fe(III)-chelate reductase activity is much more increased in roots of Citrus junos (tolerant to iron chlorosis) than in Poncirus trifoliate (susceptible to iron chlorosis). Ling et al. (2002) founded that increase of Fe(III)-chelate reductase activity was about twenty fold whereas $P$. trifoliate was stimulated to increase only about threefold at the same time and under the same conditions. The result suggest that the increase in the enzyme activity under Fe stress was an important reason for the tolerance of the Citrus junos rootstock to Fe deficiency.

It has been reported a correlation between the development of $\mathrm{Fe}(\mathrm{III})$-chelate reductase activity, acidification of the rhizosphere, and the accumulation of organic acids as citrate and malate in roots of Capsicum annum L. (Landsberg, 1986). In citrus, Fe(III)-chelate reductase activity and rhizosphere acidification have been reported to be induced in roots of several rootstocks as Citrus volkameriana, Citrus taiwanica and Citrus junos by Fe-shortage (Chouliaras et al. 2004). An increase in citric acid content in parallel with an aconitase activity decrease have also been reported in roots and fruit vesicles and calli of Citrus Lemon under Fe deprivation (Shlizerman et al., 2007). Aconitase catalyses the conversion of citrate into isocitrate, requiring Fe for its activity. Cytosolic aconitase represents a regulatory link between Fe homeostasis and organic acid metabolism. Under Fe shortage the enzyme loses 
its enzymatic activity and binds to RNA of genes involved in Fe homeostasis, altering their expression (Hentze \& Kuh 1996). In Fe-sufficient conditions, during the first half of fruit development, the decrease in the mitochondrial aconitase activity could play a role in the citric acid accumulation in the vacuole of the sac cells of the fruit (Sadka et al. 2000). During the second half of fruit development, the activity of the cytosolic aconitase increases, playing a role in acid decline. Shlizerman et al. (2007) studied the relation between the aconitase activity and the citric acid content that takes place after Fe deprivation. Cytosolic aconitase is more susceptible than mitochondrial one to Fe shortage. They demonstrate that only cytosolic activity was affected by Fe limitation whereas mitochondrial one was not. The reduction in the activity of the cytosolyc aconitase results in a decrease of the citrate catabolism, what account for the increase in pulp acidity of citrus fruit detected in trees grown in Fe deficiency. The authors observed that the application of Fe treatments during fruit maturation can reduce the acid content of the fruit juice what is an important practical question as in many scions as sweet oranges or clementines, high acid contents reduces the quality of the mature fruits delaying the harvest. However no data exist about this acid content decline is due to an activation of the cytosolic aconitase activity in the fruits.

Organic acid accumulation has in addition been interpreted in terms of the $\mathrm{pH}$-stat theory (Sakano, 1998). The $\mathrm{pH}$ of the root cytosol and vacuole increases a consequence of the apoplast acidification that occurs in response to Fe deficiency (Espen et al., 2000). This argument is supported by the fact that Fe deficiency stress correlates with and increase in Phospoenolpyruvate carboxylase (PEPC) activity, resulting in an increased nonphotosynthetic carbon fixation and a net carbon fluxes toward organic acid production (De Nisi \& Zocchi, 2000).

The adaptative changes in strategy I plants include morphological changes in the root of Fe.deficient plants. Such morphological changes have been reported for other plants as Arabidopsis, Ficus or sunflower (Römheld \& Marschner, 1981, Rosenfield et al., 1991, Schmidt et al. 2000). Typical morphological changes included additional cell division in the rhizodermis layer and enhanced formation of root hairs. In citrus, there is currently no
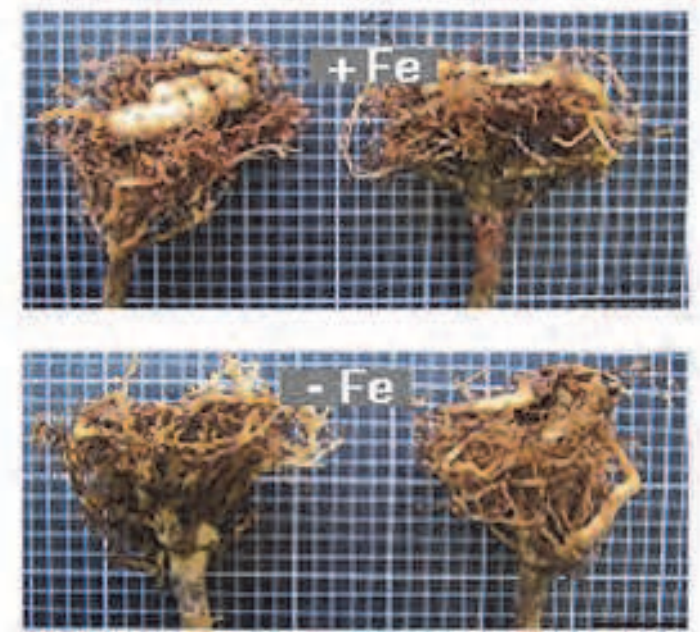

Fig. 3. Root morphology of Fe-sufficient and Fe-deficient Poncirus trifoliata plants 
report about morphological changes in the root caused by iron deficiency. In the susceptible rootstock Poncirus trifoliata, Forner-Giner et al. (unpublished data) have not observed morphological changes in roots due to iron starvation (Fig 1). Changes occurring in citrus roots of susceptible plants are mainly at a molecular level. Forner-Giner et al. (2010), in a genomic survey, found that within the genes that were differentially expressed in the plant in response to iron deficiency, a large group had to do with cell wall (Table 1).

\begin{tabular}{|l|c|c|}
\hline \multicolumn{1}{|c|}{ Gene ID } & Best Arabidopsis BLAST hit & Cell Wall Component \\
\hline C31502B08 & Calmodulin-regulated Ca(2+)-pump & pectin \\
\hline C05811H06 & polygalacturonase (pectinase) & pectin \\
\hline C05140C08 & $\begin{array}{c}\text { SYR1, Syntaxin Related Protein 1, also } \\
\text { known as PEN1 }\end{array}$ & xyloglucan \\
\hline C05133B06 & endo-xyloglucan transferase & xyloglucan \\
\hline C19009B12 & xyloglucan endotransglucosylase & \begin{tabular}{c} 
culle \\
\hline
\end{tabular}
\end{tabular}

Table 1. Cell wall related gene that are overspressed in response to Fe-deficiency

By specific staining for each component, they demonstrated that the cell wall becomes thinner in Poncirus plants under iron starvation and they also highlight that pectin and xyloglucan component changed in these plants. As it is shown in figure 2, ruthenium red staining (specific for pectin) revealed the thinning of the cell wall in the Fe deficient plants.
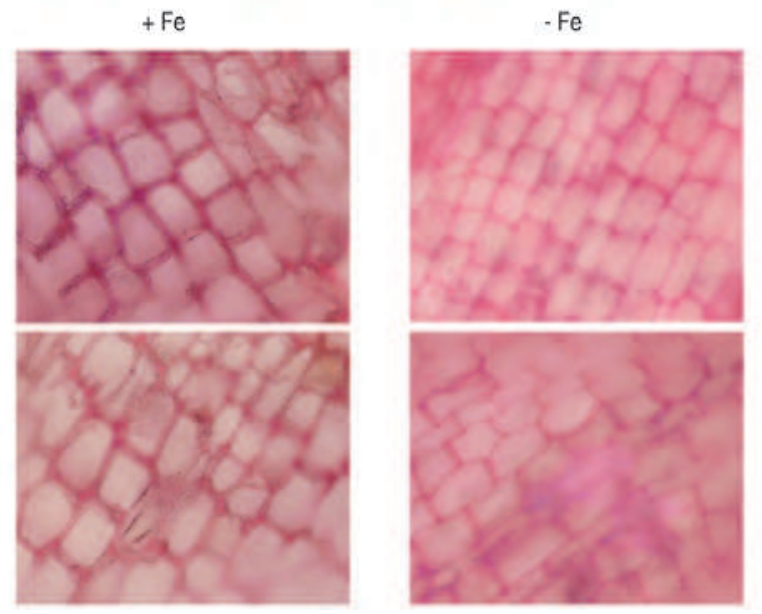

Fig. 4. Ruthenium red staining in roots of Poncirus trifoliate treated with (control) or without Fe-EDDHA (iron deficiency)

Moreover, calcofluor (a dye specific for various beta-D-glucans including Xyloglucans) stained the cell wall of the roots of more intensely than those of control plants (fig. 3). 

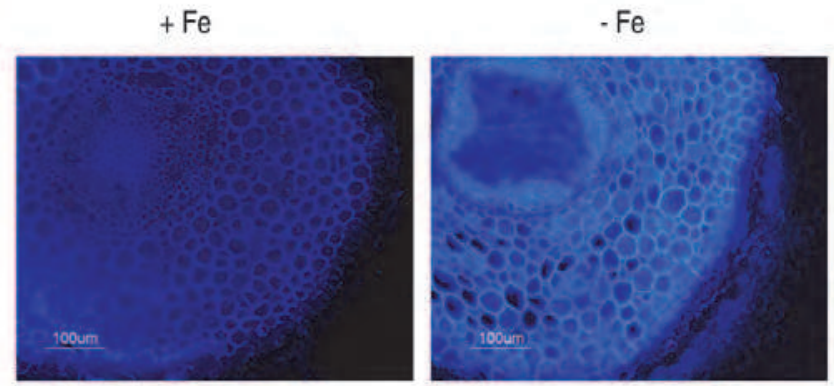

Fig. 5. Calcofluor staining in roots of Poncirus trifoliate treated with (control) or without FeEDDHA (iron deficiency)

The composition of the cell wall and the cross-linking of the different polymers that form it, most probably determine the wall mechanical properties. So that, one may hypothesize that this changes may occur because the plasticity of the cell wall there must be probably important for plant acclimation to iron deficiency (as well as to other environmental conditions). However, whether this is a mechanism to improve adaptation to iron shortage or it is a final consequence of the stress produced by the iron deficiency is still unknown and it will have to be elucidated in the future.

As for other plants, some authors have found an important decrease in soluble and ionically-bound-to-cell-wall peroxidase activities in citrus in response to Fe-deficiency (Chouliaras et al. 2004, Forner-Giner et al. 2010). As to ionically-bound-to-cell-wall peroxidases are implied in lignin metabolisms and several cell wall modifications are taking place in response to iron deficiency, one may infer that this component is being also altered during the response process. However no changes in lignin accumulation could be

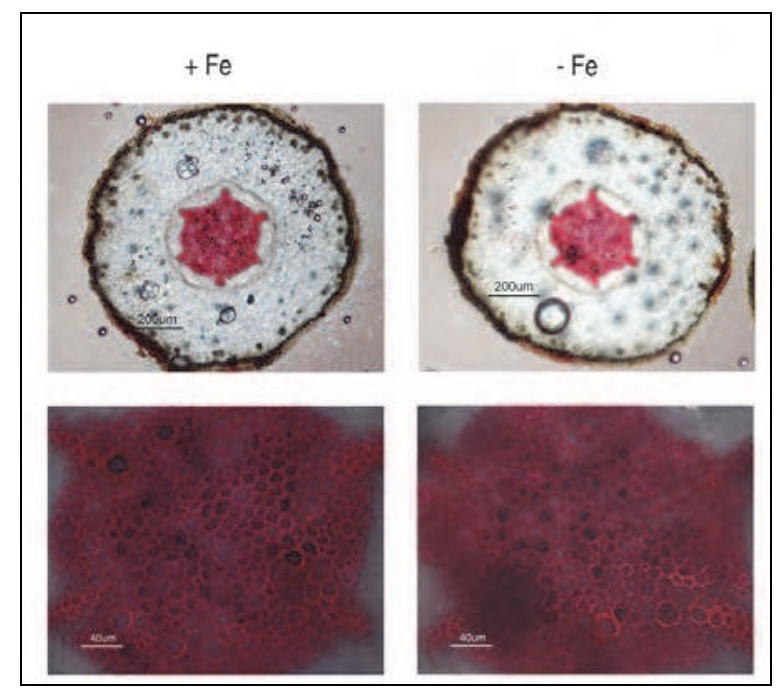

Fig. 6. Phoroglucinol staining in roots of Poncirus trifoliate treated with (control) or without Fe-EDDHA (iron deficiency) 
appreciated (fig 4) when root sections of control and Fe-deficient plants of $P$. trifoliate were stained with phoroglucinol (a specific dye that stains lignified tissue red and leaves everything else unstained) and visualised under the microscopy (Forner-Giner \& Ancillo, unpublished).

Peroxidase activity is also responsible of the conversion of $\mathrm{H}_{2} \mathrm{O}_{2}$ into water by oxidizing various hydrogen donor molecules such as phenolic compounds and auxin metabolites (Dunand et al. 2007). As in other plants, in citrus, the Fe-related decline of peroxidase activity coincide with a significant decline in catalase activity (Chouliaras et al. 2004, FornerGiner et al. 2010), which is also involved in $\mathrm{H}_{2} \mathrm{O}_{2}$ metabolism. In maize, the decrease in these enzymatic activities entails an increase in the concentration of $\mathrm{H}_{2} \mathrm{O}_{2}$ and superoxide anion radical $\left(\mathrm{O}^{2-}\right)$ that causes oxidative stress in Fe- deficient plants (Tewari et al. 2005). No direct evidences of the $\mathrm{H}_{2} \mathrm{O}_{2}$ increase have been published in citrus, but Forner-Giner et al. (2010) reported the induction, in response to Fe-deficiency, of a NADPH thioredoxin reductase $\mathrm{C}$ which is involved in reduction of $\mathrm{H}_{2} \mathrm{O}_{2}$. All together, these results suggest that the reduction in the level of catalase and peroxidase activities in iron-deficient citrus plants produce an increase of $\mathrm{H}_{2} \mathrm{O}_{2}$ and other ROS that could lead to oxidative stress and, as reported for other plants (Perez-Ruiz et al., 2006) the induction of NADPH thioredoxin reductase C may be part of the response of the plant to prevent damage by the oxidative stress caused by iron deficiency. Chouliaras et al. (2004) founded that peroxidase and catalase activities were higher in the case Citrus taiwanica ( a tolerant rootstock) rather than in Citrus volkameriana (a non-tolerant one). They propose that the ability of plants to synthesize more peroxidase and catalase could be a feature associated with tolerance to Fe deficiency.

\section{Future research and conclusion}

Iron is an essential nutrient playing critical roles in life-sustaining processes. Due to its ability to gain and lose electrons, iron works as a cofactor for enzymes involved in a wide variety of oxidation-reduction reactions (as photosynthesis, respiration, hormone synthesis, and DNA synthesis, etc). This essential role made of iron an absolutely required nutrient, and its deficiency causes iron chlorosis which seriously constraints the normal development of the plant. Iron chlorosis is a widespread problem especially for regions where the bioavailability of iron in soil is low. Usual remediation strategies consist of amending iron to soil, which is an expensive practice. Thus genetically improved chlorosis resistant rootstocks and new cultivar/rootstock combinations offer the best solution to iron chlorosis and is one of the most important lines of investigation needed to prevent this nutritional problem nowadays. However tolerant rootstocks are difficult to develop when not available and mean a long-term approach. Therefore, there is a need for new methods to diagnose and correct this nutritional disorder.

The use of microarray techniques revealed changes in gene expression level due to $\mathrm{Fe}$ deficiency and has allowed insights into the transcriptional regulation of some functions. These studies have extended our knowledge of citrus response to iron deficiency. These experiments have identified candidate genes and processes for further experimentation to increase our understanding of citrus response to iron deficiency stress.

It is likely that more extensive microarray analysis, coupled with a suitable annotation of the citrus genome, which has recently been completely sequenced, will prove invaluable in future studies of iron-stress responses in plants. Thus, while the use of functional genomic approaches to study iron-stress responses in plants already has yielded important 
information, the continued development of resources promises to yield many more insights in the future. Information gained from studies of this type may allow the development of citrus plants that are capable of growth on soils that are iron-deficient.

\section{Acknowledgment}

MA Forner-Giner and G Ancillo are recipient of a contract from Conselleria de Agricultura, Pesca y Alimentación (Generalitat Valenciana, Spain) under Proy_IVIA09/05 and Proy_IVIA09/03 respectively. The authors would like to thank Prof. L Navarro and E Primo for critical reading of the manuscript.

\section{References}

Abadìa J, Lopez-Millan A, Rombola A, \& Abadìa A (2002). Organic acids and Fe deficiency: a review. Plant Soil 241: 75-86.

Agustí, M.( 2003). Citricultura. Ed. Mundi-Prensa. Madrid. Spain.

Amorós, M. (1995). Producción de agrios: 286. Ediciones Mundi-Prensa. Madrid, Spain.

Bienfait, H.F., Bino, R.J., Van Der Bliek, A.M., Duivenvoorden, J.F., \& Fontaine, J. M. (1983). Characterization of ferric reducing activity in roots of Fe deficient Phaseolus vulgaris, Physiol. plant. 59: 196.

Castle, W.S. (1987). Citrus rootstocks. En: Rootstocks for Fruits Crops. pp. 361-369. Rom R.C. \& Carlson R.F. (eds). John Wiley \& Sons, New York.

Castle, WS, Nunnallee, J., \& Manthey JA.(2009). Screening citrus rootstocks and related selections in soil and solution culture for tolerance to low-iron stress. Hortscience 44(3): 638-645.

Chaney, R.L., Brown, J.C., \& Tiffin, L.O. (1972). Obligatory reduction of ferric chelates in iron uptake by soybean. Plant Phys 50:208-213.

Chen, Y., Barak, P. (1982). Iron nutrition of plants in calcareous soils. Advances in agronomy. 35: 217-240.

Chouliaras V., Dimassi K., Therios I., Molassiotis A., \& Diamantidis G. (2004). Root-reducing capacity, rhizosphere acidification, peroxidase and catalase activities and nutrient levels of Citrus taiwanica and C. volkameriana seedlings, under Fe deprivation conditions. Agronomie 24:1-6.

Cianzio, S.R. (1995). Strategies for the genetic improvement of Fe efficiency in plants. In: Abadía J. (Ed.). Iron Nutrition in Soils and Plants. Kluwer Academic Publishers, Dordrecht, Netherlands. 119-125.

De Nisi P., \& Zocchi G.(2000). Phosphoenolpyruvate carboxylase in cucumber (Cucumis sativus L.) roots under iron deficiency: activity and kinetic characterization. J Exp Bot.; 51:1903-1909.

Díez-Altarés, M. (1959). Fotodescomposición de clorofila en casos de deficiencia inducida de hierro. Ann. Estac. Exp. Aula Dei (Zaragoza). 6: 1-80.

Dunand, C., Cre`vecoeur, M., \& Penel, C. (2007). Distribution of superoxide and hydrogen peroxide in Arabidopsis root and their influence on root development: possible interaction with peroxidases. New Phytol. 174, 332-341.

Espen L, Dell'Orto M, De Nisi P, \& Zocchi G. (2000) Metabolic responses in cucumber (Cucumis sativus L.) roots under Fe-deficiency: a 31P-nuclear magnetic resonance invivo study. Planta, 210:985-992.

Fernández, V., \& Ebert, G. (2005). Foliar iron fertilization: a critical review. J. Plant Nutr. 28:2113-2124. 
Fernández-López, J.A., Almela, L., López-Roca, J.M, \& Alcaraz, C. (1991). Iron deficiency in citrus lemon: effects on photochlorophyllase synthetic pigments and chlorophyllase activity. J. Plant Nutr. 14: 1133-1144.

Forner, J.B., Forner-Giner, M.A., \& Alcaide A. (2003). Forner-Alcaide 5 and Forner-Alcaide 13: Two new Citrus rootstocks released in Spain. Hort. Sci. 38: 629-630.

Forner-Giner, M.A., Alcaide A., Primo-Millo E., \& Forner, J.B. (2003). Performance of "Navelina" orange on 14 rootstocks in Northern Valencia (Spain). Sci. Hort. 98: 223 -232.

Forner-Giner, MA., Llosá, MJ., Carrasco, J. L., Perez-Amador, M. A., Navarro, L., \& Ancillo, G. (2010). Differential gene expression analysis provides new insights into the molecular basis of iron deficiency stress response in the citrus rootstock Poncirus trifoliata (L.) Raf.. J Exp Bot 61: 483-490.

García, P., Abadía, J., \& Abadía, A. (1998). Tratamientos foliares para la corrección de la clorosis férrica. Geórgica. 6: 27-31.

González-Mas MC., Llosá MJ., Quijano A., \& Forner-Giner MA. (2009). Rootstock effects on leaf photosynthesis in Navelina trees grown in calcareous soil. Hortscience 44(2) 280-283.

Hentze MW, \& Kuh LC (1996) Molecular control of vertebrate Fe metabolism: mRNA-based regulatory circuits operated by Fe, nitric oxide, and oxidative stress. Proc Natl Acad Sci USA, 93: 8175-8182.

Heras, L., Sanz, M., \& Montañés, L. (1976). Corrección de la clorosis férrica en melocotonero y su repercusión sobre el contenido mineral, relaciones nutritivas y rendimientos. Anales de Aula Dei. 13: 261-289.

Hurley, A.K., Walser, R.H., Davis, T.D., \& Barney, D.L. (1986). Net photosynthesis and chlorophyll, and foliar iron in apple trees after injection with ferrous sulphate. HortSci. 21: 1029-1031

Jaegger, B., Goldbach, H., \& Sommer, K.. (2000). Release from lime induced iron chlorosis by cultan in fruit trees and its characterisation by analysis. Acta Hort. 531:107-113.

Jones, B.J. (2000). Hydroponics, a Practial Guide for the Soilles Grower. St. Lucie Press. U.S.A. 42-44.

Landsberg E-C (1986) Function of rhizodermal transfer cells in the FE stress response mechanism of Capsicum annuum L. Plant Physiol., 82: 511-517.

Larbi, A., Abadía, A., Abadía, J., \& Morales, F.(2006). Down co-regulation of light absorption, photochemistry, and carboxylation in Fe-deficient plants growing in different environments. Photosynth. Res. 89: 113-126.

Legaz, Z., Serna, M.D., Primo-Millo, E., \& Martin, B. (1992). Leaf spray end soil application of Fe-chelates to Navelina orange trees. Proceedings of the International Society of Citriculture. 2: 616-617.

Ling, LI, Yan-Hua, F., Xiao-Ying, L., Yan, P. \& Ze-Yang, Z. (2002). Expression of ferric chelate reductase gene in Citrus junos and Poncirus trifoliata Tissues. Journal of Integrative Plant Biology 44(7): 771-774.

Llosá MJ., Bermejo A., Cano A., \& Forner-Giner MA. The citrus rootstocks Cleopatra mandarin, Poncirus trifoliata, Forner-Alcaide 5 and Forner-Alcaide 13 vary in susceptibility to iron deficiency chlorosis. J. Am. Pomological Soc. 63(4) 160-167.

Loué, A. 1993. Oligélements en Agriculture. SCPA-Nathan, Luçon. France. 557.

Lucena J.J. (2000). Effects of bicarbonate, nitrate and other environmental factors on iron deficiency chlorosis. A review. J. Plant Nutr. 23: 1591-1606

Lucena, J.J., Romera, F.J., Rojas, C., García, M.J., Morales, M., Montilla, I., Alacántara, E., \& Pérez-Vicente, R.( 2006). Bicarbonate blocks the expression of several genes involved in the physiological responses to Fe-deficiency of strategy I plants. 13th International Symposium of Iron Nutrition and Interactions in Plants. Montpellier. France. 92. 
Marschner, H. (1995). Mineral Nutrition of Higher Plants. Academic Press, London, UK ( $2^{\circ} \mathrm{Ed}$.). 862.

Marchner H, \& Römheld V.(1995). Strategies of plants for adquisition of iron. In: Abadía J (Ed.). Iron Nutrition in Soils and Plants. Kluwer Academic Publishers, Dordrecht, Netherlands. 375-388.

Molassiotis, A., Tanou, G., Diamantidis, G., Patakas, A., \& Therios, I. (2006). Effects of 4month Fe deficiency exposure on Fe reduction mechanism, photosyntetic gas exchange, chlorophyll fluorescence and antioxidant defense in two peach rootstocks differing in Fe deficiency tolerance. J. Plant Physiol. 163: 176-185.

Moog PR, \& Brüggemann W. (1994). Iron reductase systems on the plant plasma membrane: a review. Plant Soil. 165:241-260.

Morales, F., Abadía, A., \& Abadía, J.( 1990). Characterizacion of the xanthophyll cycle and other photosynthetic pigmento changes induced by iron deficiency in sugar beet (Beta vulgaris L.). Plant Physiol. 94: 607-613.

Morales, F., Abadía, A., \& Abadía, J. (1991). Chlorophyll fluorescence and photon yield of oxygen evolution in iron-deficiency sugar beet (Beta vulgaris L.) leaves. Plant Physiol. 97: 886-893.

Morales, F., Abadía, A., Belkhodja, R., \& Abadía, J. (1994). Iron deficiency-induced changes in the photosynthetic pigmento composition of field-grown pear (Pyrus communis L.) leaves. Plant, CellsEEnvironment 17: 1153-1160.

Morales, F., Belkhoja, R.L., Abadía, A., \& Abadía, J. (2000). Photosystem II efficiency and mechanism of energy dissipation in iron-deficient, field grown pear trees (Pyrus communis L.). Photosyn. Res. 63: 9-21.

Mortvedt, J.J. (1986). Grain sorghum response to banded acid-type fertilizers in iron deficient soil. J. Plant Nutr. 11: 1297-1310.

Nishio, J.N., Abadía, J., \& Terry, N. (1985). Chlorophyll proteins and electron transport during iron nutrition-mediated chloroplast development. Plant Physiol. 78: 296-299.

Papastylianou, I. (1993). Timing and rate of iron chelate application to correct chlorosis in peanut. J. of Plant Nutr. 16: 1193-1203.

Pérez-Ruiz J. M., González M.C., Spínola M. C., Sandalio, L. M. \& Cejudo F. J. (2009) The cuaternary structure of NADPH thioredoxin reductase $\mathrm{C}$ is redox sensitive. Mol. Plant 2:457-467

Pestana, M., David, M., De Varennes, A., Abadía, J., Araújo, E., \& Faria, E.A.( 2001a). Responses of "Newhall" orange trees to iron deficiency in hydroponics: Effects on leaf chlorophyll, photosynthetic efficiency, and root ferric chelate reductase activity. J. Plant Nutr. 24: 1609-1620.

Pestana, M., Correia, P.J., De Varennes, A., Abadía, J., Araújo, E., \& Faria, E.A. (2001b). The use of floral analysis to diagnose the nutritional status of orange trees. J. Plant Nutr. 24, 1913-1823.

Pestana, M., Varennes, A., Araújo, E., \& Faria, E.A. (2003). Diagnosis and correction of iron chlorosis in fruit trees: a review. Food, Agric. \& Environ. 1: 46-51.

Pestana, M., Varennes, A., Abadía, J., \& Faria, E.A. (2005). Differential tolerance to iron deficiency of citrus rootstocks grown in nutrient solution. Sci. Hort. 104: 25-36.

Platt-Aloia, K.A., Thomson, W.W., \& Terry, N. 1983. Changes in plastid untraestructure during iron nutrition mediated chloroplast development. Protoplasma. 114: 85-92.

Rombolà, A.D., Brüggemann, W., Tagliavini, M., Marangoni, B., \& Moog, P.R. 2000. Iron source affects Fe reduction and re-greening of kiwifruit (Actinidia deliciosa) leaves. J. of Plant Nutr. 23: 1751-1765. 
Romera, F.J., Alcántara, E., \& De La Guardia., M.D. (1991). Characterization of the tolerance to iron chlorosis in different peach rootstocks grown in nutrient solution. In: Effect of bicarbonate and phosphate. Plant Soil. 130: 115-119.

Römheld V, Marschner H (1981). Iron deficiency stress induced morphological and physiological changes in root tips of sunflower. Physiol. Plant. 53(3): 354-360

Römheld, V. (1987). Existence of two difference strategies for the acquisition of iron in higher plants. Iron transport in microbes, plant and animals. G. Winkelmann. D.van der Helm, J.B. Neiland. VCH-Verlag. Weinheim. 353-374

Rosenfield CL, Reed DW, \& Kent MW. (1991). Dependency of iron reduction on development of a unique root morphology in Ficus benjamina L. Plant Physiol. 95:1120-1124.

Sakano K.(1998). Revision of biochemical pH-stat: involvement of alternative pathway metabolism. Plant Cell Physiol. 39:467-473.

Schmidt, W., \& Bartels, M. (1997.) Topography of the NADH-linked ferric chelate reductase in plasma membrane from Plantago roots. Abstracts of the IX International Symposium on iron nutrition and interactions in plants. University of Hoheneim. Stuttgart. Germany. 58.

Schmidt W, Tittel J, \& Schikora A. (2000). Role of hormones in the induction of iron deficiency responses in Arabidopsis roots. Plant Physiol. 122(4):1109-18.

Shlizerman L, Marsh K, Blumwald E, \& Sadka A. (2007). Iron-shortage-induced increase in citric acid content and reduction of cytosolic aconitase activity in Citrus fruit vesicles and calli. Physiol Plant. 131(1):72-9.

Soldatini, G., Tognini, M., Castagna, A., Baldan, B., \& Ranieri, A. (2000). Alterations in thylakoid membrane composition induced by iron starvation in sunflower plants. J. of Plant Nutrition. 23: 1717-1732

Spiller, S.C., \& Terry, N. (1980). Limiting factors in photosynthesis. II. Iron stress diminishes photochemical capacity by reducing the number of photosynthetic units. Plant Physiol. 65: 121-125.

Tagliavini, M., \& Rombolà, A.D. (2001). Iron deficiency and chlorosis in orchard and vineyard ecosystems. European Journal of Agronomy. 15: 71-92.

Terry, N. (1980). Limiting factors in photosynthesis I. Use of iron stress to control photochemical capacity in vivo. Plant Physiol. 65: 114-120.

Terry, N., \& Abadía, J. (1986). Function of iron chloroplasts. J. of Plant Nutr. 9(3-7): 609-646.

Terry, N., \& Zayed, A.M. (1995). Physiology and biochemistry of leaves under iron deficiency.In Iron Nutrition in Soils and Plants. (J. Abadía ed.). Kluwer Academic Publishers. Dordrecht. ISBN: 0-7923-2900-7: 283-294.

Treeby, M., \& Uren, N. (1993). Iron deficiency stress responses amongst Citrus rootstocks. Z. Pflanzenernahr 156:75-81.

Wallace, A. (1991). Rational approaches to control of iron deficiency other than plant breeding and choice of resistant cultivars. pp. 324-330. In Iron nutrition and interactions in plants. Y. Chen, Y. Hadar (Eds.). Kluwer Academic Publishers. Netherlands.

Wirén, N.V. (2004). Progress in research on iron nutrition and interactions in plants. Soil Science and Plant Nutr. 50(7): 955-964. 


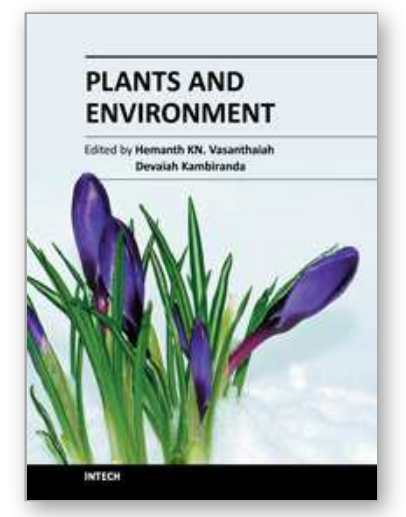

\author{
Plants and Environment \\ Edited by Dr. Hemanth Vasanthaiah
}

ISBN 978-953-307-779-6

Hard cover, 272 pages

Publisher InTech

Published online 17, October, 2011

Published in print edition October, 2011

Changing environmental condition and global population demands understanding the plant responses to hostile environment. Significant progress has been made over the past few decades through amalgamation of molecular breeding with non-conventional breeding. Understanding the cellular and molecular mechanisms to stress tolerance has received considerable scientific scrutiny because of the uniqueness of such processes to plant biology, and also its importance in the campaign â€œFreedom From Hungerâ€. The main intention of this publication is to provide a state-of-the-art and up-to-date knowledge of recent developments in understanding of plant responses to major abiotic stresses, limitations and the current status of crop improvement. A better insight will help in taking a multidisciplinary approach to address the issues affecting plant development and performance under adverse conditions. I trust this book will act as a platform to excel in the field of stress biology.

\title{
How to reference
}

In order to correctly reference this scholarly work, feel free to copy and paste the following:

Maria Angeles Forner-Giner and Gema Ancillo (2011). Iron Stress in Citrus, Plants and Environment, Dr. Hemanth Vasanthaiah (Ed.), ISBN: 978-953-307-779-6, InTech, Available from: http://www.intechopen.com/books/plants-and-environment/iron-stress-in-citrus

\section{INTECH}

open science | open minds

\author{
InTech Europe \\ University Campus STeP Ri \\ Slavka Krautzeka 83/A \\ 51000 Rijeka, Croatia \\ Phone: +385 (51) 770447 \\ Fax: +385 (51) 686166 \\ www.intechopen.com
}

\author{
InTech China \\ Unit 405, Office Block, Hotel Equatorial Shanghai \\ No.65, Yan An Road (West), Shanghai, 200040, China \\ 中国上海市延安西路65号上海国际贵都大饭店办公楼405单元 \\ Phone: +86-21-62489820 \\ Fax: $+86-21-62489821$
}


(C) 2011 The Author(s). Licensee IntechOpen. This is an open access article distributed under the terms of the Creative Commons Attribution 3.0 License, which permits unrestricted use, distribution, and reproduction in any medium, provided the original work is properly cited. 